\title{
Üniversite Web Sitesi Ana Sayfalarının Kullanılabilirliğinin Değerlendirilmesi: Göz İzleme Yaklaşımı
}

\author{
Gonca Gokce Menekse Dalveren ${ }^{1 *}$, Serhat Peker ${ }^{2}$

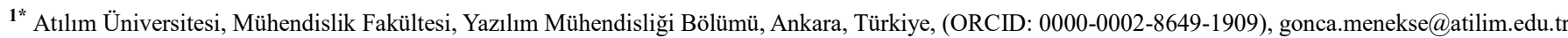 \\ 2 İzmir Bakırçay Üniversitesi, Yönetim Bilişim Sistemleri Bölümü, İzmir, Türkiye (ORCID: 0000-0002-6876-3982), serhat.peker@bakircay.edu.tr
}

(Illk Geliş Tarihi 14 Nisan 2021 ve Kabul Tarihi 7 Ağustos 2021)

(DOI: 10.31590/ejosat.915711)

\begin{abstract}
ATIF/REFERENCE: Menekse Dalveren, G.G., Peker, S. (2021). Üniversite Web Sitesi Ana Sayfalarının Kullanılabilirliğinin Değerlendirilmesi: Göz İzleme Yaklaşımı. Avrupa Bilim ve Teknoloji Dergisi, (25), 782-789.

\section{Öz}

Ziyaretçilerin ilk karşılandığı yer olan üniversite web sitesi ana sayfalarının iyi bir tasarıma sahip olması ve ziyaretçileri tarafından kullanışlı bulunması, aday öğrenci, araştırmacı, yerli ve yabancı akademik kuruluşlar gibi dış paydaşların üniversiteye olan ilgilerini artırmak ve sürekli kılmak adına oldukça kilit rol oynamaktadır. Bu motivasyondan yola çıkarak bu çalışma, seçilen beş Türk üniversitesinin ana sayfa tasarımlarını kullanılabilirlik yönünden değerlendirmeyi amaçlamaktadır. Bu amaç doğrultusunda göz izleme yaklaşımı kullanılmış, bir insan-bilgisayar etkileşimi laboratuvarındaki göz izleme cihazı ve diğer donanımlar vasıtasıyla katılımcıların ilgili web sayfalarıyla olan etkileşimlerini incelenmiştir. Deneklerin görüntüleme davranış verilerinin belirli göz hareketlerine göz izleme cihazı yazılımı kullanılarak odaklanma sayısı, ilk ziyarete kadar geçen süre, ve toplam ziyaret süresi olarak sınıflandırılmasından sonra, ANOVA methodu ile istatistiksel detaylı analizi yapılmıştır. Elde edilen bulgular, kullanıcıların ilgili sayfalardaki menü bileşenlerini bulma görevlerini yerine getirdikleri halde, bu sayfaların kullanılabilirliğinde istenilen bileşeni kısa sürede farkedememe, farklı alanlarda arama gibi zorluklarla karşılaştıklarını göstermiştir. Bu çalışma, bu alanda çalışan araştırmacılara, üniversite web sayfalarının göz izleme yöntemi ile kullanılabilirliklerinin değerlendirmesine ilişkin değerli bir referans olmasının yanı sıra paydaşların ilgisini çeken ve daha kullanıcı merkezli üniversite web sitesi ana sayfalarının tasarlanması yönünde çıkarımlar sunmaktadır.
\end{abstract}

Anahtar Kelimeler: İnsan-bilgisayar etkileşimi, Web sitesi kullanılabilirliği, Kullanıcı deneyimi, Bilgi sistemleri, Bilgi yönetimi, Göz izleme.

\section{Evaluating the Usability of University Web Site Home Pages: Eye Tracking Approach}

\begin{abstract}
The fact that the home pages of the university website, which is the first place where the visitors are welcomed, have a good design and are useful by the visitors, plays a very key role in increasing and sustaining the interest of external stakeholders such as prospective students, researchers, domestic and foreign academic institutions. Based on this motivation, this study aims to evaluate the home page designs of five selected Turkish universities in terms of usability. For this purpose, an eye tracking approach was used, and the interactions of the participants with the relevant web pages were examined through the eye tracking device and other equipment in a human-computer interaction laboratory. The findings obtained with the analysis of the viewing behavior data of the subjects showed that although the users mostly fulfilled the task of finding the menu items on the relevant pages, they encountered different difficulties in the usage of these pages. This study provides researchers working in this field as a valuable reference for the usability evaluation of the university web pages by eye tracking method, as well as implications for the design of more user-centered university homepages that attract stakeholders' attention.
\end{abstract}

Keywords: Human-computer interaction, Web site usability, User experience, Information systems, Information management, Eye tracking.

\footnotetext{
* Sorumlu Yazar: gonca.menekse@atilim.edu.tr
} 


\section{Giriş}

Günümüzde web siteleri, organizasyonların küresel pazarda aktif bir şekilde yer almalarında kilit bir öneme sahiptir. $\mathrm{Bu}$ bağlamda, üniversiteler aday öğrencilerden kendi personeline kadar tüm paydaşlarıyla iletişimde kalmak ve onlara çeşitli hizmetler sağlamak adına web sitelerini etkin bir şekilde kullanmaktadır. Aynı zamanda, web siteleri, üniversitelerin tüm faaliyetleri hakkında bilgi veren yegâne kaynak olup üniversitelerin tanıtımında hatırı sayılır düzeyde bir paya sahiptir. Tüm bu avantajlarıyla birlikte, web siteleri, üniversitelerin vazgeçilmez, hayati bir parçası ve en görünür yüzlerinden biri haline gelmiş durumdadır (Peterson, 2006). Günümüzde, gelişen internet ve bilişim teknolojileri sayesinde, üniversiteler web sayfalarını ihtiyaçları doğrultusunda farklı tasarımlarda sunabilmektedir. Diğer taraftan, paydaşlar üniversite web sitelerinde harika kullanıcı deneyimleri bekleme eğilimindedir. Bu durum, kullanıcıların beklenti ve davranışlarını dikkate alarak tasarımsal açından kullanıcı odaklı web sayfaları geliştirmeleri noktasında üniversiteler üzerinde baskı yaratmaktadır.

Kullanıcıların, bir web sitesindeki tüm sayfalara erişebilmeleri için öncelikli olarak ilgili web sitesinin ana sayfasını ziyaret etmeleri gerekmektedir. $\mathrm{Bu}$ bağlamda, ilk izlenimde önemli payı olan web sitesi ana sayfaları, ziyaretçilerin dikkatini çekmelidir (Jakob Nielsen, 2001). Ziyaretçileri ilk girişte karşılayan üniversite web sitelerinin ana sayfaları, özellikle dış paydaşlar tarafından yoğun bir şekilde incelenmekte ve bu kullanıcılar, üniversite hakkında ilk izlenimi bu sayfalar üzerinden edinmektedirler. Tasarımı iyi, kullanışlı ve profesyonel bir görünüme sahip üniversite ana sayfaları, ziyaretçilerinde olumlu bir ilk izlenim bırakacak, aday öğrenci, araştırmacı, yerli ve yabancı akademik kuruluşlar gibi dış paydaşların ilgili üniversite ile atacağı olası adımların önünü açacaktır.

Bir web sitesinin kullanılabilirliği, her zaman kullanıcıların ilgili web sitesi hakkında alg1 ve davranışlarını etkileyen büyük bir faktör olmuştur (Patterson \& Ellis, 2004). Bu bağlamda, web sitesinin kullanılabilirliği, web sitesinin tasarımında önemli rol oynamaktadır. İyi tasarlanmış bir web sitesi, kullanıcıların görevleri sorun yaşamadan başarılı bir şekilde tamamlayabilmesine olanak sağlamalıdır (Yan \& Guo, 2010). İyi tasarlanmamış bir web sitesi ise, kullanıcıların siteyi etkili ve verimli bir şekilde kullanmasını engelleyebilir ve dolayısıyla kullanıcılar web sitesini bir daha ziyaret etmek istemeyebilir. $\mathrm{Bu}$ nedenle, web kullanılabilirliğinin kullanıcı memnuniyeti üzerinde doğrudan bir etkisi bulunmaktadır. (Matera, Rizzo, \& Carughi, 2006).

Uluslararası Standardizasyon Örgütü (ISO), kullanılabilirlik, "bir ürünün, belirli kullanıcılar tarafından, belirli bir kullanım bağlamında etkinlik, verimlilik ve memnuniyetle belirtilen hedeflere ulaşmak için ne ölçüde kullanılabileceği" olarak ifade etmiştir (International Organization for Standardization, 1998). Web sitelerinin kullanılabilirliğini ölçmek için geleneksel kullanılabilirlik testi, odak grup araştırması, sesli düşünme yöntemi, gözlem, uzman değerlendirmesi, kullanıcı anketi ve göz izleme yöntemi gibi birçok yaklaşım kullanılmaktadır. Bunlar içinde geleneksel kullanılabilirlik testi en yaygın olarak kullanılan yöntem olup kullanıcıların web sitelerini ne kadar etkili (örneğin, görev başarıs1), verimli (örneğin, görevdeki süre) ve memnun (örneğin, kullanıcıların ara yüzle ilgili görüşleri) bir şekilde kullandığına ilişkin ölçümler içermektedir (Wang et al., 2019).
Geleneksel yöntemlerin yanı sıra göz izleme teknolojilerinin gelişmesi ve elverişliliği ile birlikte göz takibi yaklaşımını kullanmak, son zamanlarda kullanılabilirlik analizi çalışmalarında çok popülerdir. Bu yöntem, kullanılabilirlik değerlendirmelerinde kullanıcıların dikkat ve bilişsel süreçleri hakkında daha fazla bilgi elde etmeye olanak sağlamaktadır. Göz izleme çalışmalarında elde edilen metriklerin, genel olarak göz hareketlerindeki farklılıklar ile bağlantılı olduğu belirlenmiştir (Goldberg \& Wichansky, 2003). Bu metriklere ilişkin elde edilen veriler, kullanıcıların ara yüzde ilk nereye baktıkları, hangi alanlara daha çok odaklandıkları ve neleri göz ardı ettikleri hakkında önemli bilgiler sunmaktadır (Johansen \& Hansen, 2006; Nakatani \& Pollatsek, 2004; Russell, 2005). Ayrıca göz izleme çalışmalarından elde edilen nicel veriler, ara yüzlerin, kullanılabilirliğinin nesnel olarak değerlendirmesine olanak sağlamaktadır. (Duchowski, 2007; Poole \& Ball, 2005). Özetle sunduğu tüm bu imkanlarla birlikte, göz izleme yaklaşımı, geleneksel kullanılabilirlik testleriyle gözlemlenemeyen kullanıcı davranışlarını, keşfetmek ve derinlemesine araştırmak için kullanılabilir.

$\mathrm{Bu}$ çalışmanın amacı, göz izleme tekniğini kullanarak, üniversite web sitesi ana sayfalarını kullanılabilirlik açısından değerlendirmektir. Bunun için seçilen beş Türk üniversitesinin ana sayfa tasarımları, 31 deneğin katıldığı göz izleme deneyi ile değerlendirilmiştir. Deneyde, katılımcılardan üniversitelerin ana sayfalarında sıklıkla kullanılan menü bileşenlerini bulmaları istenmiş ve bu esnada ilgili sayfalardaki göz hareketleri kaydedilmiştir. Göz izleme deneyi sonucunda elde edilen katılımcıların görüntüleme davranış verileri odaklanma sayısı, ilk ziyarete kadar geçen süre ve toplam ziyaret süresi olarak göz izleme cihazı tarafindan sunulan yazılım ile sinıflandırıldıktan sonra istatistiksel ANOVA testi ile analiz edilmiş, seçilen üniversitelerin ana sayfa tasarımları kullanılabilirlik açısından değerlendirilmiş ve kıyaslanmıştır. Bu çalışmanın, bu alandaki araştırmacılara, üniversite web sitelerinin kullanılabilirliğinin göz izleme yaklaşımı ile değerlendirmesine yönelik bir yol haritası sağlamak ve üniversite yönetimlerine, ziyaretçilerle daha iyi etkileşim yaratan ve onlarda daha iyi izlenim bırakabilecek ana sayfa tasarım önerileri sunmak gibi teorikte ve pratikte temel katk1lar1 mevcuttur.

\section{Literatür taraması}

Yıllar içinde, farklı alanlardaki web sitelerinin kullanılabilirlik değerlendirmeleri üzerine çok sayıda araştırma yapılmıştır. Özellikle geçtiğimiz son on beş yıl süresince, web kullanılabilirlik çalışmaları, yükseköğretim kurumları üzerinde de yaygın olarak geçekleştirilmiştir. $\mathrm{Bu}$ bağlamda yapılan ilk çalışmalardan birinde, Alexander (Alexander, 2005) on beş üniversite web sitesinde (13 Avustralya sitesi, bir ABD ve İngiltere'den bir site) üç farklı kullanıcı test yöntemi (gözlem, sesli düşünme ve anket) kullanarak kullanıcı deneyimlerini araştırmış ve zayıf bilgi mimarisi, zayıf içerik, zayıf arama ara yüzü tasarımı ve PDF belgelerinin kullanımı gibi dört yaygın kullanılabilirlik problemi tespitinde bulunmuştur. $\mathrm{Bu}$ alanda yapılan bir diğer öncü çalışmada Özçelik vd. (Özçelik, Kurşun, \& Çağıltay, 2006) göz izleme yöntemini kullanarak 16 katılımcı ile birlikte dört farklı Türk üniversitesinin web sayfalarını kullanılabilirlik açısından değerlendirmişler ve elde ettikleri sonuçlar ışı̆̆ında uygulayıcılara bu yönde öneriler sunmuşlardır.

Kostaras ve Xenos (Kostaras, Kostaras, Xenos, \& Xenos, 2007) ve Du Toit ve Bothma (Du Toit \& Bothma, 2009) tarafindan 
yapılan çalışmalarda üniversite web sitelerini değerlendirmek için sezgisel değerlendirme yöntemi kullanılmıştır. Her iki çalışma da değerlendirilen web sitelerinde eski içerik, zayıf gezinme, uygunsuz menü tasarımı ile ilgili bir dizi ortak tasarım problemleri dile getirilmiştir. Mustafa ve Al-Zoua'bi (Mustafa \& Al-Zoua'bi, 2008) Ürdün'deki, Islam ve Tsuji (Islam \& Tsuji, 2011) ise Bangladeş'deki bir dizi üniversite web sitelerinin kullanılabilirliğini otomatik yazılım araçları olan HTML toolbox ve web sayfası analizi araçlarını kullanarak değerlendirmişlerdir. Mustafa ve Al-Zoua'bi (Mustafa \& Al-Zoua'bi, 2008), Ürdün web sitelerinin genel kullanılabilirlik düzeyinin kabul edilebilir olduğunu gösterirken, Islam ve Tsuji (Islam \& Tsuji, 2011), Bangladeş web siteleriyle ilgili memnuniyetsizliği ortaya çıkarmış ve bu web sitelerindeki yaygın zayıflıkları dile getirmiştir.

Çağlar ve Mentes (Caglar \& Mentes, 2012), çekicilik, kontrol edilebilirlik, verimlilik, yararlılık ve öğrenilebilirlik olmak üzere beş temel faktöre dayanan WAMMI anketini kullanarak Lefke Avrupa Üniversitesi web sitesini kullanılabilirlik yönünden değerlendirmiştir. Elde edilen sonuçlar, LAÜ web sitesinin genel kullanılabilirlik düzeyinin kullanıcıları tatmin etmediğini göstermiş ve bu sonuçlara dayanarak, kullanıcı memnuniyeti ve kullanılabilirliği iyileştirmek için bir dizi kılavuz önerilmiştir. Benzer şekilde, Mentes ve Turan (Mentes \& Turan, 2012) da Namık Kemal Üniversitesi web sitesinin kullanılabilirliğini ölçmek için aynı anket tekniğini (WAMMI) kullanmıştır. Bu çalışmada, ek olarak kullanıcıların kullanılabilirlik algısını etkileyebilecek olası faktörlerde (cinsiyet, yaş, internet deneyimi vb.) incelenmiştir. Sonuçlar, cinsiyet ve internet kullanım deneyiminin, kullanıcıların kullanılabilirliğe ilişkin algılarını etkilediğini ortaya koymuştur.

Alotaibi (Alotaibi, 2013) Suudi Arabistan'daki bir dizi özel ve devlet üniversitesi web siteleri üzerine otuz katılımcıyla sezgisel kullanılabilirlik değerlendirmesi üzerine bir çalışma yürütmüştür. Sonuçlar, ülkedeki kullanıcı dostu üniversite web siteleri tasarlama ve geliştirme yönünde olumlu bir girişim olduğunu gösterirken, devlet üniversitesi web sitelerinin özel üniversite web sitelerine göre daha kullanışlı olduğu görülmüştür. Bir diğer çalışmada, Tüzün vd. (Tüzün, Akinci, Kurtoğlu, Atal, \& Pala, 2013) Hacettepe Üniversitesi Öğrenci İşleri Daire Başkanlığı web sayfasında on öğrencinin bilgi arayışını, göz izleme ve sesli düşün protokolü yöntemleri ile incelemiştir. Göz izleme veri analizi, öğrencilerin arama görevlerini gerçekleştirirken sık sık web sitesinin ana sayfasını aşağı ve yukarı kaydırdıklarını ortaya çıkarmıştır.

Rahman ve Ahmed (Rahman \& Ahmed, 2013) Bangladeş'deki Dakka Üniversitesi web sitesinin kullanılabilirliğini değerlendirmek için dört farklı kullanılabilirlik ölçeğinden (Kullanıcı Arayüzü Memnuniyeti Anketi, akademik web siteleri için JISC kontrol listesi, QUIS ve WAMMI) faydalanmıştır. Elde edilen sonuçlar, çoğu katılımcının, ilgili üniversite web sitesinden memnun kalmadıklarını ve buna bağlı olarak web sitesinin özellikle içerik kalitesi yönünden iyileştirilmeye ihtiyacı olduğunu ortaya koymuştur. Hasan (Hasan, 2014) Ürdün'deki dokuz farklı üniversite web sitesinin kullanılabilirliğini, gezinme, mimari, kullanım ve iletişim kolaylığı, görsel tasarım ve içerikten oluşan beş temel kullanılabilirlik faktörünü kullanarak değerlendirmiştir. Elde edilen sonuçlar, katılımcıların test edilen web sitelerinin içeriğinden ve gezinmesinden (kullanım kolaylı̆̆ı) memnun olduğunu, ancak web sitelerinin tasarımından memnun olmadığını göstermiştir.

e-ISSN: 2148-2683
Peker vd. (Peker, Kucukozer-Cavdar, \& Cagiltay, 2016) beş farklı Türk üniversitesinin web sitelerinin kullanılabilirliğini değerlendirmiş ve karşılaştırmıştır. $\mathrm{Bu}$ araştırmada, web sitesi kullanımındaki kullanıcı memnuniyetini değerlendirmek için anket, seçilen görevlerle kullanıcı performansını ölçmek için kullanıcı testi uygulanmıştır. Çalışmanın sonuçları, seçilen üniversite web sitelerinin çok sayıda kullanılabilirlik sorunu yaşadığını ortaya koymuştur. Benzer şekilde, Melgarejo vd. (Torres Melgarejo, Zapata Del Río, \& Quispe Vilchez, 2019) Peru üniversitelerinde, kullanıcılarla web varlığı ve kullanılabilirliğini değerlendirmiş ve bunların ilişkisini incelemiştir. Üniversite web sitelerinin kullanılabilirliği üzerine yapılan son araştırmalardan birinde ise Huang ve Bilal (Huang \& Bilal, 2019) Tennessee Üniversitesi web sitesinin işe alım web sayfalarına ilişkin kullanıcı deneyimini, röportaj ve göz izleme teknikleriyle ölçmüştür. Bulgular, öğrencilerin web sitelerini kullanabildikleri ve arama görevlerinin çoğuna cevap bulabildikleri halde, bu web sitelerinin kullanılabilirliğiyle ilgili zorluklarla karşılaştıklarını göstermiştir.

Görüldüğü üzere literatürde hali hazırdaki çalışmalar, üniversite web sitelerinin kullanılabilirliğini çeşitli yöntemlerle değerlendirirken, bu çalışmalardan sadece birkaçı göz izleme yaklaşımını kullanmıştır. Ayrıca, üniversite ana sayfalarının kullanılabilirliğine ilişkin yapılan çalışmaların sayısı da oldukça sınırlıdır. Bunların yanı sıra, Türkiye'deki üniversitelerin ana sayfalarının kullanılabilirliğini, göz izleme yaklaşımını kullanarak değerlendiren bir çalışma daha önce yapılmamıştır. Literatürdeki bu boşluğu doldurmak adına bu çalışma, Türkiye'deki üniversite ana sayfalarının kullanılabilirliğini göz izleme tekniği yordamıyla incelemeyi amaçlamaktadır. $\mathrm{Bu}$ motivasyonlardan yola çıkarak mevcut çalışma bu boşlukları doldurmayı amaçlamaktadır.

\section{Materyal ve Metot}

$\mathrm{Bu}$ çalışmada, seçilen üniversitelerin ana sayfa tasarımları kullanılabilirlik açısından değerlendirilmiştir. $\mathrm{Bu}$ amaçla, katılımcıların yer aldığı göz izleme deneyi düzenlenmiş ve bu deneyde, deneklerin ilgili web sayfalarıyla olan etkileşimi sırasında görüntüleme davranış verileri kaydedilmiştir. İzlenen yönteme ilişkin önemli hususlar ve adımların ayrıntılı açıklaması aşağıdaki alt başlıklarda sunulmaktadır.

\subsection{Ana sayfa menu bileșenleri ve üniversiteler}

Üniversite web sitesi ana sayfalarının kullanılabilirlik değerlendirmesini yapmak üzere öncelikle katılımcılara verilecek arama görevlerine ilişkin menü bileşenleri belirlenmiştir. $\mathrm{Bu}$ menü bileşenlerinin, üniversite ana sayfalarının genelinde bulunmasına ve ziyaretçiler tarafından sıklıkla kullanılan veya ihtiyaç duyulan işlemlere ilişkin olmasına dikkat edilmiştir (Özçelik, Kurşun, \& Çağıltay, 2006). Bu amaçla, "Adaylar”, "Akademik", "Arama Alanı", "Dil Seçeneği", ve "Kampüs Hayatı" olmak üzere beş adet menü bileşeni belirlenmiştir.

Bir diğer önemli nokta ise kullanılabilirlik değerlendirmesine ilişkin çalışmada kullanılacak üniversiteleri belirlemektir. $\mathrm{Bu}$ çalışma kapsamında değerlendirilen üniversite web siteleri QS World 2019 sıralamasına (Rankings, 2019) göre belirlenmiştir. Bu sıralamaya göre Türkiye'nin en iyi beş üniversitesinin web siteleri çalışmaya dahil edilmiştir. Bu üniversiteler ve ana sayfalarına ilişkin linkler Tablo 1'de verilmiştir. 
Tablo 1: Ana sayfaları dĕgerlendirilen üniversiteler

\begin{tabular}{|l|l|}
\hline Üniversite & Link \\
\hline Bilkent & http://www.bilkent.edu.tr/ \\
\hline Boğaziçi & https://www.ku.edu.tr/ \\
\hline Koç & http://www.metu.edu.tr/tr \\
\hline ODTÜ & https://www.sabanciuniv.edu/ \\
\hline Sabancı & \\
\hline
\end{tabular}

\subsection{Katılımcılar}

Bu çalışma, toplam 31 gönüllü katılımcı ile yapılmıştır. Tüm denekler Helsinki Bildirgesi'ne uygun olarak sözlü bilgilendirilmiş onam vermişlerdir. Tüm istatistiksel analizler, 16'sı erkek, 15'i kadın olmak üzere toplam 31 katılımcının deneysel verilerine dayanılarak yapılmıştır. $\mathrm{Bu}$ örneklem büyüklüğü, genellikle nispeten küçük boyuttaki katılımcılarla yürütülen nitel ve keşifsel göz izleme çalışmaları için yeterli kabul edilmektedir (Wedel ve Pieters, 2008b). Katılımcıların yaşları 19 ile 26 arasında değişmekte, ortalama 22.13 olup ( $\mathrm{SS}=2.15$ ), yaşın sonuçlar üzerindeki potansiyel dişsal etkilerini azaltmak için makul bir örneklemdir. Tüm katılımcılar gözlük veya kontakt lens takarak düzeltilmiş normal veya normal görmeye sahiptirler. Dahası, hepsi sağ elini kullanmakta ve Batı sistemi gibi soldan sağa okuma davranışına sahiptirler.

\subsection{Veri toplama araçları}

Deneyler, Atılım Üniversitesi SimLab'da sessiz bir odada gerçekleştirilmiştir. Bu odada bulunan deney araçları, 1366-768 piksel ekran çözünürlüğüne sahip bir Tobii X60 göz takip cihazı, bir masaüstü bilgisayar ve bir 18,5 inç LED monitörden oluşmuştur. Tüm bu cihazlar birbirine bağlanmıştır. Göz izleyicinin örnekleme frekansı $60 \mathrm{~Hz}$ ve doğruluk seviyesi 0,5 derecedir. Ayrıca, uyarıcıları sunmak, göz takip cihazını kalibre etmek, katılımcı göz hareketleri ve odaklanma davranışları ile ilgili verileri kaydetmek ve tanımlayıcı istatistikler oluşturmak için Tobii Studio Yazılımı kullanılmıştır.

\subsection{Deney tasarımı ve veri toplama süreci}

Araştırmanın temelini oluşturan deneyin tasarımında oldukça dikkatli davranılmıştır. Gerçek deneyden önce, deney ortamını ve koşullarını değerlendirmek ve daha da önemlisi, her bir web sayfasının ne kadar süreyle gösterilmesi gerektiğine karar vermek için beş katılımcı ile yapısı ve içeriği gerçek deneyle birebir aynı olan bir pilot çalışma gerçekleştirilmiştir.

Gerçek deney bir dizi adımdan oluşmuştur. İlk olarak, katılımcılara deneysel prosedür ve göz izleme cihazı hakkında bilgi verilmiştir. Katılımcılardan araştırmaya gönüllü olarak katıldıklarını belirten bilgilendirilmiş onamları alınmıştır. Katılımcılar bilgisayar ekranının önündeki sabit bir sandalyeye oturtulmuştur ve oturma pozisyonları monitörün önünde $70 \mathrm{~cm}$ mesafede ortalanacak şekilde ayarlanmıştır. Standartlaştırılmış ekran parlaklığı ve ortam 1şı̆̆ sağlanmıştır ve katılımcılara deney sırasında ekrana bakmaları talimatı verilmiştir. Göz izleme cihazı monitörün altına yerleştirilmiş ve göz izleyicinin katılımcıların göz hareketlerini doğru bir şekilde kaydetmesini sağlamak için bir kalibrasyon işlemi gerçekleştirilmiştir.

Kalibrasyon sonuçları standartlara ulaştıktan sonra, ilgili web sayfaları katılımcıların dikkatine sunulmuştur. Her bir web sayfasında, katılımcılar sırasıyla istenen menü bileşenlerini bulmaya çalışırken, bu esnada göz hareketleri göz izleme cihazı tarafından kayıt altına alınmıştır. Katılımcıların pilot çalışmadaki web sayfalarını görüntülerken harcadıkları ortalama süre 20 saniye olduğundan, beş üniversite ana sayfasındaki her bir menü bileşeni otomatik olarak 20 saniye süreyle görüntülenmiştir. $\mathrm{Bu}$ şekilde 20 saniyeden uzun izleme süreleri katılımcıların sıkılmasına, görsel olarak yorulmalarına ve konsantrasyonlarını kaybetmelerine neden olabilmektedir. Ayrıca, sonuçlarda olası bir yanlılığa mahal vermemek adına deneylerde üniversite sayfaları beş farklı kombinasyonda kullanıcılara sunulmuştur. Her bir web sayfası ekranda görünmeden önce, katılımcıların web sayfalarının belirli noktalarına odaklanmalarını önlemek için 3 saniye boyunca beyaz bir arka plan görüntüsünde kırmızı bir daire sunulmuş ve bu dairenin içinde katılımcılardan bulunması istenen menü bileşeni belirtilmiştir. Böylece katılımcıların dikkati aynı yere çekilmiştir.

\subsection{Göz izleme ölçütleri ve veri analizi}

Dikkat düzeyi, daha önce tanımlanmış olan İlgi Alanları'ndaki göz hareketi verileri kullanılarak ölçülmüştür. Tüm araştırma disiplinlerinde, İlgi Alanları, göz hareketi ölçümleri sunulan uyaranın bölümleriyle ilişkilendirilmek için kullanılmaktadır ve uyaranların en alakalı kısımlarını belirlemek için ayrı ayrı tanımlanmaktadırlar (Hessels, Kemner, van den Boomen, \& Hooge, 2016). Bu çalışmada, İlgi Alanları deney tasarım aşamasında tanımlanmıştır. Tobii Studio Yazılımı, İlgi Alanları'nın analizde kullanılacak şekilde tanımlamasına olanak tanımaktadır. İlgi Alanları, bir web sayfasının belirli içeriğine karşılık gelen küçük bölümler ve geometrik alanlardır (Şekil 1). Göz hareketlerini analiz etmek için, deneylerden önce her web sayfası menü bileşeni için İlgi Alanları tanımlanmıştır. Tanımlanan İlgi Alanları şu şekildedir: "Adaylar", "Akademik", "Arama", "Dil seçeneği” ve "Kampüs hayatı". Şekil 1'de Bilkent Üniversitesi web sayfasında belirlenmiş olan menü bileşenleri İlgi Alanları gösterilmektedir. $\mathrm{Bu}$ İlgi Alanları deney tasarım aşamasında numaralandırılmış ve analizler bu İlgi Alanları'ndaki göz hareketleri incelenerek yapılmıştır. Web sayfası menü bileşenlerinin görüntülenmesi sırasında katılımcıların odaklanma noktaları ve süreleri izlenmiştir. Göz izleme çalışmalarında, odaklanma, bir katılımcının gözünün belirli bir İlgi Alanı'nda belirli bir süreden fazla duraklaması anlamına gelmektedir.

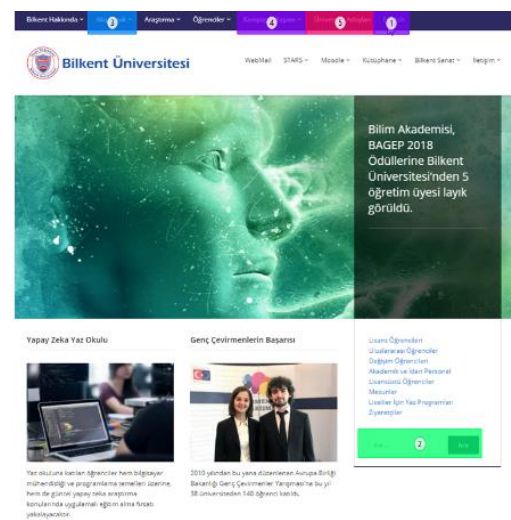

Şekil 1. Bilkent Üniversitesi web sayfası menü bileşeni için İlgi Alanı tanımları

Katılımcıların her bir İlgi Alanı'na verdikleri ilgiyi değerlendirmek için, Tobii Studio Yazılımı tarafindan oluşturulan üç ortak göz hareketi değişkeni kullanılmıştır. Bunlar, odaklanma sayısı (OS), ilk ziyarete kadar geçen süre (IZS) ve toplam ziyaret süresi (TZS) olarak belirtilmiştir. OS, belirli bir İlgi Alanı 
üzerindeki odaklanma sayısıdır. Bir İlgi Alanı'nın OS ne kadar yüksekse, izleyici için o kadar çekici olmaktadır. IZS, bir uyaran ekranının başlangıcından katılımcının İlgi Alanı'na ilk kez odaklanmasına kadar geçen süredir. İlgi Alanı'nın IZS'si kısaysa, bu bölgenin çok dikkat çekici olduğunu göstermektedir. TZS, belirli bir İlgi Alanı içindeki tüm ziyaretlerin süresidir ve belirli bir İlgi Alanı'ndaki daha uzun TZS, o alan için daha fazla süre harcandığını göstermektedir.

Bu göz hareketi değişkenlerinin verileri analiz için önceden işlenmiş ve ardından istatistiksel analiz, Windows için SPSS yazılım paketi (sürüm 22; IBM Corporation, New York, ABD) kullanılarak gerçekleştirilmiştir. Konumların web sayfası menü bileşenlerine verilen görsel dikkat üzerindeki etkisini değerlendirmek için, her bir katılımcı için tüm katılımcıların göz hareketi verileri üzerinde bir dizi tekrarlanan ölçüm varyans analizi (RM-ANOVA) (denekler içi faktör için) testi yapılmıştır. Anlamlı ANOVA sonuçları göz önüne alındığında, farklılıkların ikili karşılaştırmalarını araştırmak için Bonferroni post hoc testleri ve istatistiksel analiz için .05 alfa seviyesi kullanılmıştır. Ayrıca, bu çalışmada Tobii Studio Yazılımı ile 1sı haritaları oluşturulmuştur. Göz izleme araştırmalarındaki 1sı haritaları kullanıcıların bakış dağılımının niteliksel izlenimini göstermektedir. Gözlem süresi boyunca bakış pozisyonlarının toplanması ve odaklanılan alanların belirlenmesi ile 1sı haritası oluşturulur. Katılımcıların göz hareketlerinden oluşturulan 1sı haritaları kullanılarak katılımcıların web sayfalarındaki göz hareketi davranışları incelenmiştir.

\section{Bulgular}

Beş üniversite web sayfasının her birinin İlgi Alanı için OS, TZS ve IZS ölçümlerinin ortalamaları aşağıdaki şekillerde gösterilmiştir. Şekil 2 ve 3, hangi web sayfası elemanının en yüksek odaklanma sayısına ve ziyaret süresine sahip alan olduğunu göstermektedir. "Adaylar" web sayfası İlgi Alanı için Boğaziçi Üniversitesi, “Akademik” web sayfası İlgi Alanı için Koç Üniversitesi, "Arama Alanı" İlgi Alanı için Bilkent Üniversitesi, "Dil Seçeneği” ve "Kampüs Hayatı” web sayfası İlgi Alanları için Odtü en yüksek odaklanma sayısına sahiptir. Bu, hangi web sayfası elemanın en çekici alan olduğunu, hangi alanların ise en az ilgi gören alan olduğunu göstermiştir.

Üniversite ana sayfalarının İlgi Alanları'nın IZS değerlerinin sonuçları, Koç Üniversitesi'nin tüm web sayfası menü bileşenleri için en yüksek IZS değerlerine sahip olduğunu ortaya koymuştur. Bu sonuç, Koç Üniversitesi ana sayfası menü bileşenlerinin diğer üniversitelere göre daha fazla zamanda fark edildiğini, dolayısıyla daha az dikkat çekici olduğunu düşündürmüştür. IZS analiz sonuçları ayrıca "Akademik" ve "Kampüs Hayatı" alanlarının diğer web sayfası unsurlarına göre daha erken fark edildiğini göstermiştir.

Üniversite ana sayfalarının her bir İlgi Alanı tarafından yakalanan dikkat üzerinde önemli bir etkisi olup olmadığını belirlemek için, tanımlanan beş İlgi Alanı'nın her biri için göz izleme verileri üzerinde RM-ANOVA'lar gerçekleştirilmiştir. Tablo 2'deki post-hoc karşılaştırmalar sütununda ilgili varsayımları doğrulanmış ve anlamlı bir farkı yansıtan post hoc testlerinin sonuçları verilmiştir. Sonuçlar, beş web sayfası menü bileşeninin tümü için beş üniversite arasında önemli farklılıklar ortaya koymuştur. IZS ölçüsü ile ilgili olarak üniversite web sayfalarının "Adaylar" $(\mathrm{F}(105.273)=13.717, \mathrm{p}<.001)$, "Akademik" $(\mathrm{F}(22.705)=15.997, \mathrm{p}<.001)$, "Arama Alanı" $(\mathrm{F}$ $(488.250)=27.019, \mathrm{p}<.001)$ ve "Dil Seçeneği" $(\mathrm{F}(134.439)=$ e-ISSN: 2148-2683
8.401, $\mathrm{p}<.001)$ menü bileşenlerine ilişkin sonuçlar Tablo 2'de belirtilmiştir. Ayrıca OS ölçümü ile ilgili olarak sonuçlar yine Tablo 2'de gösterilmiştir, "Arama Alanı" ve "Dil Seçeneğii” menü bileşenleri için sırasıyla $(\mathrm{F}(25.229)=10.619, \mathrm{p}<.001))$, $(\mathrm{F}$ $(17.230)=7.976, p<.001)$ değerleri bulunmuş ve görsel ilgi üzerinde önemli etkinin olduğunu göstermiştir. Ek olarak, TZS ölçümüne ilişkin sonuçlar, web sayfası menü bileşeni "Arama Alanı" na gösterilen görsel ilgi üzerinde önemli bir etkisi olduğunu da göstermiştir $(\mathrm{F}(3.733)=7.841, \mathrm{p}<.001))$.

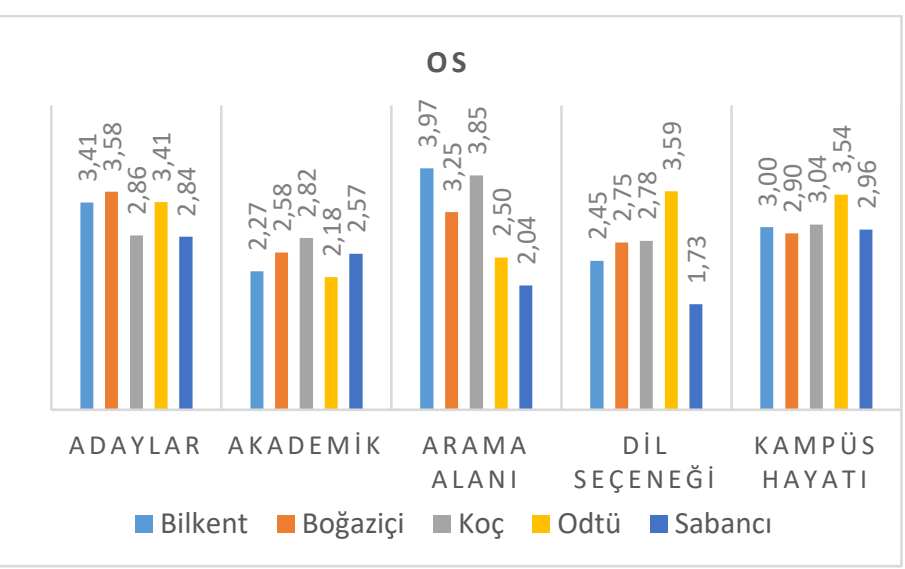

Şekil 2. Beş İlgi Alanı'nda odaklanma sayısının üniversitelere göre dă̆ılımı

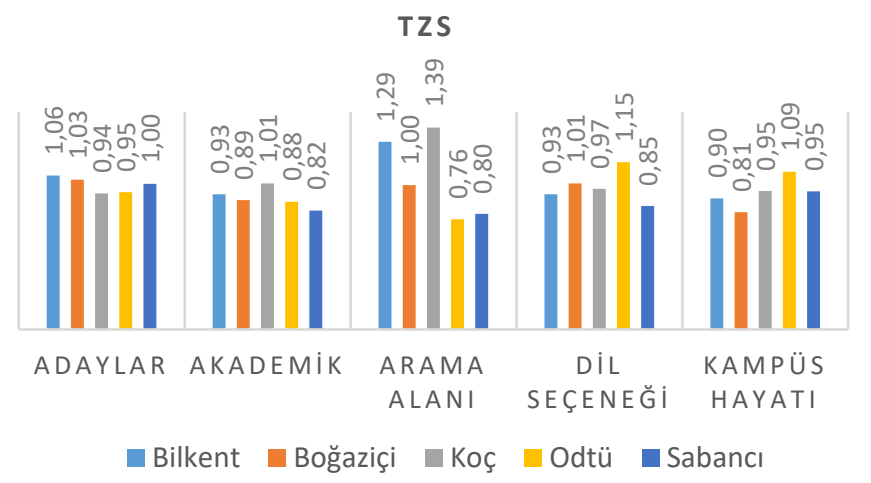

Şekil 3. Beş İlgi Alanı'nda toplam ziyaret süresinin üniversitelere göre dă̆llımı

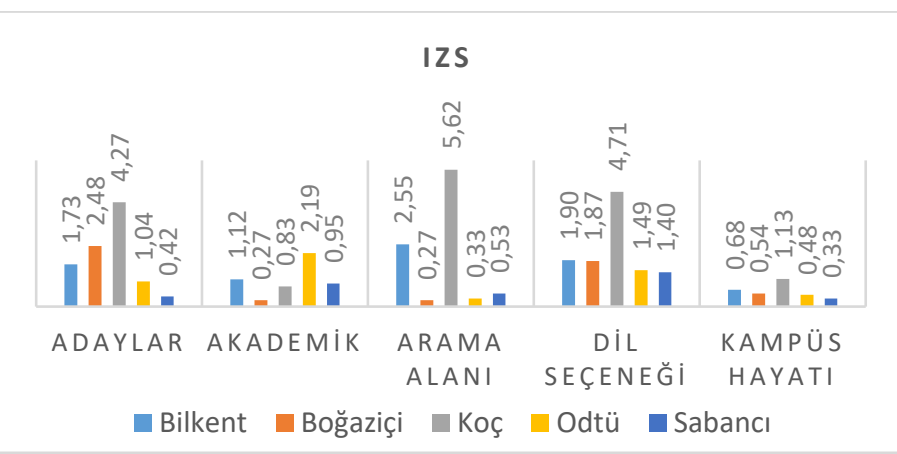

Şekil 4. Beş Ilgi Alanı'nda ilk ziyarete kadar geçen sürenin üniversitelere göre dă̆ılımı 
Tablo 2. Ana sayfa tasarımlarının görsel dikkat üzerindeki etkisini gösteren test sonuçları

\begin{tabular}{|c|c|c|c|}
\hline İlgi Alanı & Ölçüt & $\mathbf{F}$ & Post-hoc karşılaştırmaları a \\
\hline Adaylar & IZS & 13.717 & $\begin{array}{l}\text { Bilkent }<\text { Koç, Odtü }<\text { Koç, } \\
\text { Sabanc1 }<\text { Koç, } \\
\text { Sabanc1 }<\text { Boğaziçi, } \\
\text { Sabanc1 }<\text { Odtü }\end{array}$ \\
\hline Akademik & IZS & 15.997 & $\begin{array}{l}\text { Boğaziçi< }<\text { Bilkent, } \\
\text { Bilkent }<\text { Odtü, Boğaziçi< }<\text { Koç, } \\
\text { Boğaziçi< }<\text { Odtü, } \\
\text { Boğaziçi }<\text { Sabancı, Koç }<\text { Odtü, } \\
\text { Sabancı }<\text { Odtü }\end{array}$ \\
\hline
\end{tabular}

IZS 27.019 Boğaziçi<Bilkent,

Bilkent $<$ Koç, Odtü $<$ Bilkent, Sabanci<Bilkent,

Boğaziçi<Koç, Odtü<Koç,

Sabanci<Koç,

\begin{tabular}{cccc}
$\begin{array}{c}\text { Arama } \\
\text { Alanı }\end{array}$ & OS 10.619 & $\begin{array}{l}\text { Odtü<Bilkent, } \\
\text { Sabanci<Bilkent, } \\
\text { Sabanci<Boğaziçi, Odtü<Koç, } \\
\text { Sabanci<Koç, }\end{array}$ \\
\cline { 2 - 4 } TZS 7.841 & $\begin{array}{l}\text { Odtü<Bilkent, } \\
\text { Sabanci<Bilkent, Odtü<Koç, } \\
\text { Sabanci<Koç, }\end{array}$
\end{tabular}

\begin{tabular}{lccl}
\hline & IZS & 8.401 & $\begin{array}{l}\text { Boğaziçi<Koç, Otü<Koç, } \\
\text { Sabanci<Koç }\end{array}$ \\
\cline { 3 - 4 } $\begin{array}{l}\text { Dil } \\
\text { Seçeneği }\end{array}$ & OS & 7.976 & $\begin{array}{l}\text { Sabancı< }<\text { Boğaziçi, } \\
\text { Sabanci<Koç, Sabancı<Odtü }\end{array}$
\end{tabular}

$\mathrm{a}<$ önemli bir farkı yansıtır

$\mathrm{p}<.001$

\section{Tartışma}

$\mathrm{Bu}$ çalışmadan elde edilen sonuçlara göre, IZS verileri değerlendirildiğinde Sabancı Üniversitesi'nin ana sayfasının menü bileşenleri daha hızlı fark edilmiş, bunu sırasıyla Boğaziçi ve Odtü Üniversiteleri takip etmiştir. IZS değeri en fazla olan üniversite, Koç Üniversitesi olmuştur. Ayrıca elde edilen sonuçlardan menü bileşenlerinin ana sayfanın hangi kısımlarına yerleştirildiğinin görsel dikkat üzerinde önemli etkisinin olduğu anlaşılmıştır. Menü bileşenlerinin sayfanın üst kısmında belirli aralıklar ile verilmiş olması katılımcıların aranan menü bileşenini daha hızlı bulmalarını sağlamıştır. IZS değerleri tüm üniversiteler için menü bileşenleri arasında değerlendirildiğinde ise en hızlı bulunan menü bileşeninin "Kampüs Hayatı" menü bileşeni olduğu görülmüştür. $\mathrm{Bu}$ bileşenin genellikle seçilen tüm üniversite sayfalarında menü alanının ortasında yer alması fark edilmesini kolaylaştırmıştır. Isı haritaları katılımcıların gösterilen web sayfası üzerinde hangi alanlara odaklandıklarını görsel olarak belirten haritalardır. Bu haritalarda kırmızı renk en uzun bakılan yerleri, sarı ve yeşil sırasıyla kısa ve daha kısa bakılan yerleri belirtmektedir. Şekil 5 'te verilen ısı haritasında da görüldüğg̈ gibi katılımcıların sayfanın farklı alanlarına odaklanmadan "Kampüs Hayatı" menü bileşenini fark ettiklerini ve bu alana daha fazla odaklandıklarını söylemek mümkündür.

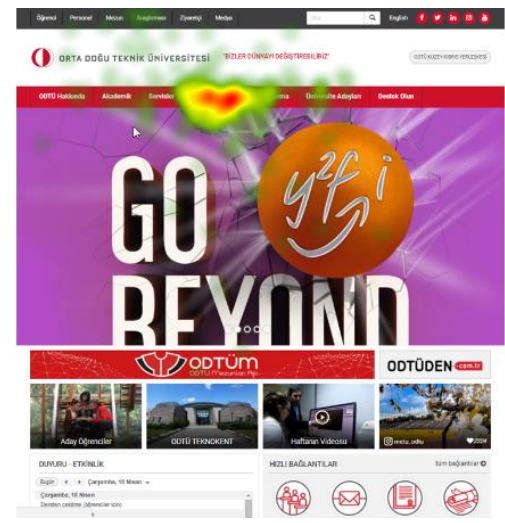

\section{Şekil 5. Odtü “Kampüs Hayatı” menu bileşeni ısı haritası}

Elde edilen sonuçlara göre, IZS değeri en yüksek olan menü bileşeni ise "Arama Alanı" olmuştur. Seçilen üniversitelerin "Arama Alanı" bileşenleri sayfalarda farklı alanlarda konumlandığından bu alanın bulunması zaman almıştır. "Arama Alanı" menü bileşeni Bilkent Üniversitesi web sayfasında sağ alt köşede verilmiştir. Menü bileşenlerinin genellikle web sayfalarının üst bölümünde bulunmasına bağlı olarak katılımcıların "Arama Alanı" menü bileşenini sayfanın üst kısmında arayarak vakit kaybettikleri söylenebilir. Sayfanın üst kısmında arama yaptıktan sonra bulunması istenilen menü bileşenini fark edip bu alana odaklandıkları Şekil 6'da verilen 1sı haritasından anlaşılmaktadır.
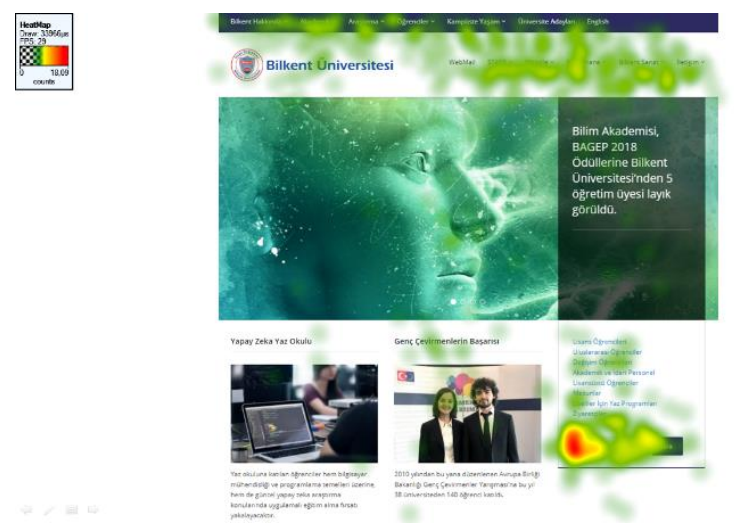

\section{Şekil 6. Bilkent "Arama Alanı” menü bileşeni ısı haritası}

OS değerleri ele alındığında en az OS'nın Sabancı Üniversitesi’nde olduğu görülmüştür. Bunu Boğaziçi ve Bilkent Üniversiteleri takip etmiştir. Bu sonuca göre menü bileşenlerinin bulunma kolaylıkları sayfadaki OS ile bağlantılıdır denilebilir. İstenilen menü bileşenini bulmak için sayfada arama yapıldığı sırada ilgisiz alanlara odaklanılmış olması ve sayfadaki odaklanma sayısını artırmaktadır. Bu durum en fazla OS'na sahip olan Koç Üniversitesi'nde görülmüştür. Katılımcılar menü bileşenlerini ararken daha fazla noktaya odaklanarak OS sayısını artırmışlardır.

Üniversite web sayfalarını TZS değerleri ile karşılaştırdığımızda en fazla TZS'nin Koç Üniversitesi'ne, en az TZS değerinin ise Sabanc1 Üniversitesi'ne ait olduğu görülmüştür. Bu durumda menü bileşenlerinin hızlı bulunmaları katılımcıların web sayfası ziyaret sürelerini etkilemiştir. Kullanım kolaylığı olan menülerin, web sayfalarında istenen bileşeni 
bulmak için harcanan süreyi kısalttığı görülmüştür. Böylece, katılımcılar amaçlanan bağlantıya daha hızlı erişmiş ve bilgiye ulaşım kolaylaşmıştır.

\section{Sonuç}

Günümüzde insanların bilgiye erişimi internet ortamında daha yaygın hale gelmiştir. Bu deneyimi daha etkili ve kolay hale getirmek için insan davranışlarının incelenmesi gereklilik arz etmektedir. Bu nedenle kullanıcıların web sayfalarındaki bilgiye ulaşma davranışlarını inceleyerek web sayfalarını daha etkili ve anlaşılır hale getirmek mümkündür.

Üniversite web sitesi ana sayfaları, tüm web site ana sayfalarında olduğu gibi gelen ziyaretçileri ilk karşılayan sayfalar olup ziyaretçilerin aradığını bulup bulamayacağı, nasıl bir deneyim yaşayacağı ve üniversite hakkında edinecekleri ilk intiba hususlarında etkin öneme sahiptir. $\mathrm{Bu}$ açıdan, üniversite ana sayfalarının ziyaretçilerinin aradığını bulabileceği, kullanıcı dostu bir tasarıma sahip olmaları oldukça mühimdir. Bu çalışmada, üniversite web sitesi ana sayfalarının sundukları kullanıcı deneyimi ve kullanılabilirlikleri, günümüzde popülaritesi giderek artan göz izleme yaklaşımı vasıtasıyla değerlendirilmiştir. Bu kapsamda, gerekli ekipmanlara sahip bir insan-bilgisayar etkileşimi laboratuvarında katılımcıların dahil olduğu deneyler düzenlenmiştir. Deneylerde, katılımcılar ilgili üniversite ana sayfalarında sıklıkla kullanılan menü bileşenlerini bulmaya çalışmışlar ve bu deneyimleri sırasında, deneklerin göz hareketlerine ilişkin veriler toplanmıştır. Katılımcılar bu görevleri gerçekleştirirken bir göz izleme cihazı ile göz hareketleri kaydedilmiş ve analiz edilmek üzere belirli göz hareketi değişkenine sınıflandırılmıştır. Çeşitli göz izleme metriklerine ilişkin elde edilen bu veriler istatistiksel olarak analiz edilmiş ve 1sı haritaları gözlemlenmiştir.

Çalışmadan elde edilen sonuçlara göre bulunması istenen menü bileşeninin ve üniversite web sayfasının göz hareketi değişkenleri üzerinde etkisinin olduğu görülmüştür. Analiz sonuçlarından elde edilen verilere göre menü bileşenlerinin eşit aralıklar ile yan yana verilmesi kullanım kolaylığı ve katılımcıların istenilen bilgiye daha hılı erişmelerini sağlamıştır. $\mathrm{Bu}$ durum web sayfasında harcanan toplam süreyi kısaltmaktadır. Web sayfasındaki bilgilerin ve menü bileşenlerinin yerleşimleri ziyaret sürelerini etkilemektedir sonucuna varılabilir.

Bu çalışmadan elde edilen bulgular, üniversiteler için pratik sonuçlara sahiptir. Üniversiteler, ana sayfalarının etkinlik düzeylerini inceleyebilir ve web sayfalarının kullanılabilirliğini artırarak kullanıcı memnuniyetlerini yükseltebilirler. Dahası, üniversite web geliştiricileri daha etkili ve kullanıcı dostu web siteleri tasarlayabilirler. İleriki zamanlarda bu çalışma daha fazla üniversite web sayfası kullanılarak daha yüksek katılımcı sayısı ile tekrarlanarak sonuçların doğruluğu artırılabilir. Web sayfalarında bulunması istenilen menü bileşeni ve bağlantı sayısının artırılması da kullanıcı davranışlarını belirlemede faydalı olacaktır. Bunlara ek olarak kullanılan göz izleme cihazının etkinliğinin de sonuçlar üzerinde önemli bir etkisi olduğu söylenebilir. Teknolojinin de ilerlemesi ile daha doğru ve güvenilir kayıt yapabilen göz izleme cihazları üretilmektedir. Ayrıca, benzer çalışma farklı alanlarda hizmet veren kuruluşlar için de uygulanabilir olması açısından süreklilik arz etmektedir.

\section{Teşekkür}

Araştırma süresince değerli destekleri ve katkıları için Dr. Yavuz İNAL'a teşekkür ederiz.

\section{Kaynakça}

Alexander, D. (2005). How usable are university websites? A report on a study of the prospective student experience. AusWeb05: 11th Australasian World Wide Web Conference.

Alotaibi, M. B. (2013). Assessing the usability of university websites in Saudi Arabia: A heuristic evaluation approach. Proceedings of the 2013 10th International Conference on Information Technology: New Generations, ITNG 2013. https://doi.org/10.1109/ITNG.2013.26

Caglar, E., \& Mentes, S. A. (2012). The usability of university websites - A study on European University of Lefke. International Journal of Business Information Systems. https://doi.org/10.1504/IJBIS.2012.048340

Du Toit, M., \& Bothma, C. (2009). Evaluating the usability of an academic marketing department's website from a marketing student's perspective. International Retail and Marketing Review.

Duchowski, A. (2007). Eye tracking methodology: Theory and practice. In Eye Tracking Methodology: Theory and Practice. https://doi.org/10.1007/978-1-84628-609-4

Goldberg, J. H., \& Wichansky, A. M. (2003). Eye Tracking in Usability Evaluation. A Practitioner's Guide. In The Mind's Eye: Cognitive and Applied Aspects of Eye Movement Research. 4/50027-X

Hasan, L. (2014). Evaluating the Usability of Educational Websites Based on Students' Preferences of Design Characteristics. International Arab Journal of E-Technology.

Hessels, R. S., Kemner, C., van den Boomen, C., \& Hooge, I. T. C. (2016). The area-of-interest problem in eyetracking research: A noise-robust solution for face and sparse stimuli. Behavior Research Methods, 48(4), 1694-1712. https://doi.org/10.3758/s13428-015-0676-y

Huang, L. M., \& Bilal, D. (2019). Usability of University Recruitment Web Pages from International Doctoral Students' Perspectives. Lecture Notes in Computer Science (Including Subseries Lecture Notes in Artificial Intelligence and Lecture Notes in Bioinformatics). https://doi.org/10.1007/978-3-030-23535-2_37

International Organization for Standardization. (1998). ISO $9241-$ 11: Ergonomic requirements for office work with visual display terminals (VDTs) - part 11: guidance on usability. International Organization for Standardization. https://doi.org/10.1038/sj.mp.4001776

Islam, A., \& Tsuji, K. (2011). Evaluation of Usage of University Websites in Bangladesh. DESIDOC Journal of Library \& Information https://doi.org/10.14429/djlit.31.6.1322

Technology.

Jakob Nielsen. (2001). 113 Design Guidelines for Homepage Usability (Jakob Nielsen).

Johansen, S. A., \& Hansen, J. P. (2006). Do we need eye trackers to tell where people look? Conference on Human Factors in Computing Systems - $\quad$ Proceedings. https://doi.org/10.1145/1125451.1125630

Kostaras, N., Kostaras, N., Xenos, M., \& Xenos, M. (2007). Assessing Educational Web-site Usability using Heuristic Evaluation Rules. Evaluation. 
Matera, M., Rizzo, F., \& Carughi, G. T. (2006). Web usability: Principles and evaluation methods. In Web Engineering. https://doi.org/10.1007/3-540-28218-1_5

Mentes, S. A., \& Turan, A. H. (2012). Assessing the usability of university websites: An empirical study on Namik Kemal University. Turkish Online Journal of Educational Technology.

Mustafa, S. H., \& Al-Zoua'bi, L. F. (2008). Usability of the academic websites of Jordans' Universities An evaluation study. Conference: 9th International Arab Conference for Information Technology(ACIT'2008)., At Tunisia.

Nakatani, C., \& Pollatsek, A. (2004). An eye movement analysis of "mental rotation" of simple scenes. Perception and Psychophysics. https://doi.org/10.3758/BF03196848

Özçelik, E., Kurşun, E., \& Çağıltay, K. (2006). Göz Hareketlerini İzleme Yöntemiyle Üniversite Web Sayfalarının İncelenmesi. Akademik Bilişim 2006 Bildiriler Kitapçilgi.

Patterson, K., \& Ellis, A. (2004). Usability and meeting the needs of educational Web site users. Proceedings of the Tenth Australian World Wide Web Conference.

Peker, S., Kucukozer-Cavdar, S., \& Cagiltay, K. (2016). Exploring the relationship between web presence and web usability for universities: A case study from Turkey. Program. https://doi.org/10.1108/PROG-04-2014-0024

Peterson, K. (2006). Academic Web site design and academic templates: Where does the library fit in? Information Technology and Libraries. https://doi.org/10.6017/ital.v25i4.3354

Poole, A., \& Ball, L. J. (2005). Eye tracking in HCI and usability research. In Encyclopedia of Human Computer Interaction. https://doi.org/10.4018/978-1-59140-562-7.ch034

Rahman, M. S., \& Ahmed, S. M. Z. (2013). Exploring the factors influencing the usability of academic websites: A case study in a university setting. Business Information Review. https://doi.org/10.1177/0266382113482557

Rankings, Q. W. university. (2019). QS World university rankings 2019. https://doi.org/10.1201/9781315155890-7

Russell, M. C. (2005). Hotspots and Hyperlinks: Using Eyetracking to Supplement Usability Testing. Usability News.

Torres Melgarejo, L., Zapata Del Río, C., \& Quispe Vilchez, E. (2019). Exploring the Relationship Between Web Presence and Web Usability in Peruvian Universities. Lecture Notes in Computer Science (Including Subseries Lecture Notes in Artificial Intelligence and Lecture Notes in Bioinformatics). https://doi.org/10.1007/978-3-030-23535-2_43

Tüzün, H., Akinci, A., Kurtoğlu, M., Atal, D., \& Pala, F. K. (2013). A study on the usability of a university registrar's office website through the methods of authentic tasks and eye-tracking. Turkish Online Journal of Educational Technology.

Wang, J., Antonenko, P., Celepkolu, M., Jimenez, Y., Fieldman, E., \& Fieldman, A. (2019). Exploring Relationships Between Eye Tracking and Traditional Usability Testing Data. International Journal of Human-Computer Interaction. https://doi.org/10.1080/10447318.2018.1464776

Yan, P., \& Guo, J. (2010). The research of web usability design. 2010 The 2nd International Conference on Computer and Automation Engineering, ICCAE 2010. https://doi.org/10.1109/ICCAE.2010.5451619 